\title{
Influence of occupancy on building energy performance: a case study from social housing dwellings in Perth, Western Australia
}

\author{
Parisa Esmaeilimoakher* , Tania Urmee, Trevor Pryor, and Garry Baverstock \\ School of Engineering and Information Technology, Murdoch University, Perth, Western Australia, Australia
}

Received: 27 February 2017 / Received in final form: 4 July 2017 / Accepted: 4 July 2017

\begin{abstract}
Worldwide, the residential sector is a substantial energy consumer mainly due to the requirements of space heating and cooling, lighting and electronic appliances in the building. In Australia, the residential sector accounts for a significant proportion of final energy consumption, with a significant proportion of this energy attributed to space conditioning. Appliances including lighting, refrigeration, water heating, cooking and standby power also factoring into the energy used in Australian households. In response to sharp rises in energy prices in recent years, many households are taking steps to reduce their energy consumption. Many are investing in energy efficient appliances, home upgrades, installing rooftop solar panels, etc. However, low income can become a barrier, preventing many people from investing in energy efficiency as a way of reducing costs. This paper is a part of a broader study aiming to identify the areas of energy inefficiency in social housing dwellings, and improve the overall efficiency through modifying occupants' energy use culture. The firsthand information on where and how energy is used in the dwellings was collected through conducting walk-through energy audits in the sample dwellings. This information was then combined with the information provided by the households' representatives on the time of use of their appliances as well as direct observations to calculate energy consumption in these households. Practical guidelines were then proposed, taking into account their energy use behaviour to minimize their energy consumption at a minimum cost.
\end{abstract}

\section{Introduction}

Annual Energy Account by the Australian Bureau of Statistics in 2017 revealed that on average, each Australian household used just 117 GJ of energy throughout 2014/15 [1]. It is well established that energy consumption in the residential sector offers an important opportunity for conserving resources [2]. Australian's household energy consumption has increased slightly over the last decade. Data from the Bureau of Resources and Energy Economics showed that Australian households' energy consumption, excluding fuels used for transport purposes, grew by $54 \mathrm{PJ}$ (14\%) between 2000-01 and 2010-11 (from 398 to $452 \mathrm{PJ}$ ). The fuels with the greatest increase in household consumption over this period were electricity $(25 \%$, from 179 up to $223 \mathrm{PJ}$ ) and natural gas (22\%, from 122 up to 148 PJ).

Households use energy for a wide variety of purposes ranging from heating and cooling, water heating, lighting, different electronic appliances and equipment including refrigeration and cooking appliances. Figure 1 presents the breakdown of average energy use in a typical Australian home in 2008.

\footnotetext{
* e-mail: p.esmaeilimoakher@murdoch.edu.au
}

As shown in Figure 1, space heating/cooling (38\%), water heating $(25 \%)$ and electronic appliances $(16 \%)$ are stood among the three most energy intensive appliances.

The amount of energy used in a household is influenced by different factors such as the number of people living in the household, the fuels used, the efficiency of the building and appliances and the behaviour of the building users and how efficiently they use energy. For a building to be energy efficient, all these factors are needed to be addressed at the same level of importance. However, changing some of the factors towards more efficient building is difficult or sometimes impractical. For example, once the building is constructed, the elements of building design that are needed to be taken into account during design and construction phase such as orientation, insulation level, etc., would be unchangeable, unless major renovation was undertaken. The efficiency of the appliances and how efficiently they are used in the households, however, are some of the major areas leading to improved energy efficiency in dwellings during different stages. Energy audit and investigation of historical energy consumption are the two important steps in understanding the total energy use pattern of dwellings. Generally, the process encompasses inspecting, surveying and analysing energy flows in the building aiming to reduce the amount of energy used in the 


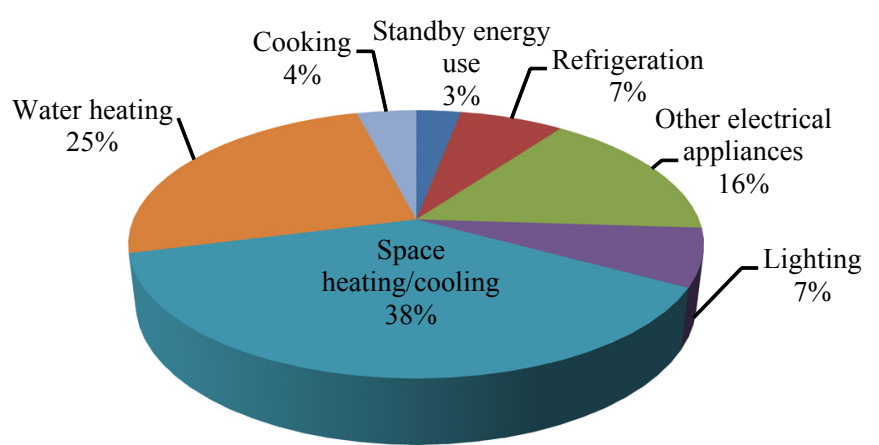

Fig. 1. Breakdown of average energy use in a typical Australian dwelling (source: Government of South Australia).

building without negatively affecting the services provided. Auditing is therefore, an ideal way of identifying energy management opportunities through systematic gathering and evaluation of energy data in buildings.

Residential energy consumption is not only influenced by building characteristics, but also through socioeconomic characteristics of the building users, their behaviour, and efficiency of the service system [3]. The complexity of these factors alongside with unpredictability of the user behaviour makes residential energy performance highly complicated in nature. Using information provided by the households, this paper presents the results of energy audit in the sample dwellings and provides an overview of the distribution of electricity consumption in the households in summer and winter. This paper is developed in four sections. The first section sets out the background for the paper. The methodology used to establish a clear picture of energy consumption in the sample dwellings is described in Section 2. In Section 3, the results have been discussed followed by Section 4 that concluded the paper.

\section{Methodology}

Figure 2 summarizes the methodology used in this paper.

Walk-through energy audit in each dwelling started with discussing the step by step process involved with the household's representative. Before commencement of the actual audit, all the households' auditing questions were responded by the research team. Permission from each representative was also sought to access their household's online utility bills in order to investigate the quantities and cost of energy input in the building and annual and seasonal changes in energy use and cost. The walk-through audit was then started by creating a detailed list of energy consuming appliances, and the information required for calculating their energy consumption as shown on the appliances labels (such as wattage, voltage, and ampere). Similarly, the details of lighting fixtures were listed out in each dwelling. The households were then questioned about how the appliances were used by the occupants in their household. This information included the time of use of the appliances, the number of loads each appliance was used per day, the average time of use, the star-rating (where applicable), the annual energy consumption and the standby status of the appliances when they are not in use.
When the required information was collected on-site, historical electricity consumption data (as the main source of energy in almost all Australian households) was extracted from households' online bills during 2013 and 2014. Subsequently, the ADEC by different electronics was calculated in terms $\mathrm{kWh} /$ day during a sample summer and winter day. The process was then followed by identifying the distribution of electricity consumption by different electronics in each sample households and proposing guidelines for further energy conservation in the households.

\section{Results and discussion}

\subsection{Historical electricity consumption analysis}

Two years (2013-14) of electricity consumption data was extracted from households' online bills and summarized in the form of the mid-point of billing period and ADEC $/ \mathrm{m}^{2}$ (kWh) for each household (Figs. 3 and 4).

Households were grouped into two groups based on their ADEC $/ \mathrm{m}^{2}$ : the extreme electricity users and regular electricity users (see Figs. 3 and 4). As shown in Figures 3 and 4 , the $\mathrm{ADEC} / \mathrm{m}^{2}$ by regular electricity users ranged between 0.02 and $0.1 \mathrm{kWh} / \mathrm{m}^{2}$. It, however, exceeded from $0.1 \mathrm{kWh}$ and reached to $0.29 \mathrm{kWh} / \mathrm{m}^{2}$ by some of the extreme electricity users. Electricity consumption in different households followed different trends. Unlike the households that experienced their highest consumption in summer (e.g., HH13, HH3, HH9), others consumed more electricity during cold winter days (HH10, HH7, HH12). As shown in Figures 3 and 4, electricity consumption in some households followed a steadier trend. For example, as it can be seen in Figure 4, no clear peak is detected in the electricity consumption by HH1, HH3, HH4, etc. However, other households including HH5 experienced sudden changes in their consumption during the period under investigation.

\subsection{Analysis of walk-through energy audit}

A walk-through audit was conducted with the main focus on generating information on the electricity consumption in the households living in social housing dwellings. The audit was executed during 2014 and 2015 calendar year. Out of 17 households participated in the survey, 2 households had recently moved to their current house and therefore, no historical utility information was available for them. Furthermore, two more households did not authorise the research team to have access to their utility information. By removing these four households, the number of households for walk-through energy audit stood at 13 households (Tab. 1).

In the walk-through audit conducted in the sample dwellings, appliances such as refrigerators, fridge-freezers and freezers were classified as "Refrigeration". Fans, heaters, reverse cycle air-conditioners and evaporative coolers, on the other hand; fell into the "Heating and Cooling" classification. "Entertainment" included iPads, laptops, personal computers, radios, DVD players, VCRs, 


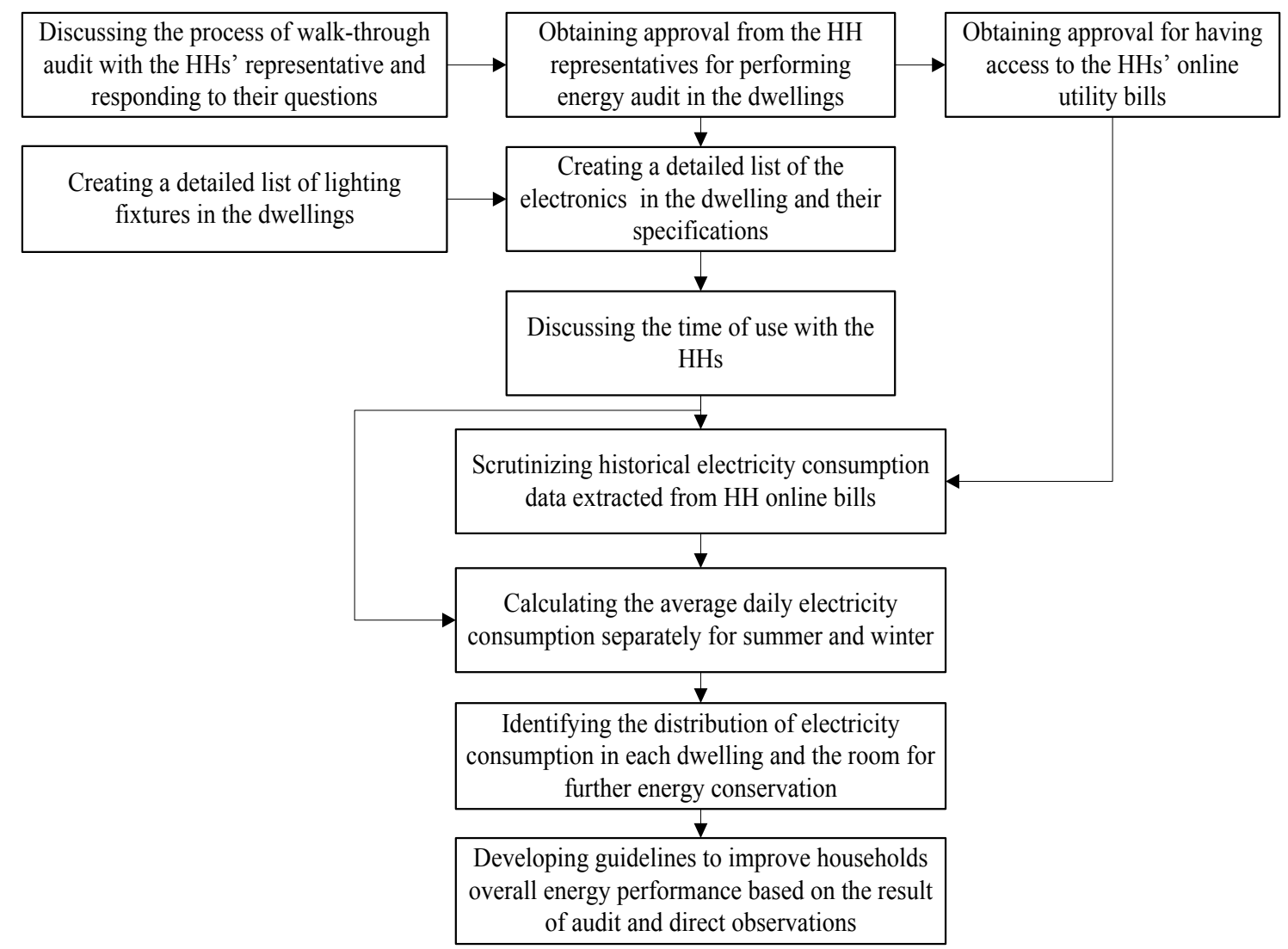

Fig. 2. Methodology flowchart.

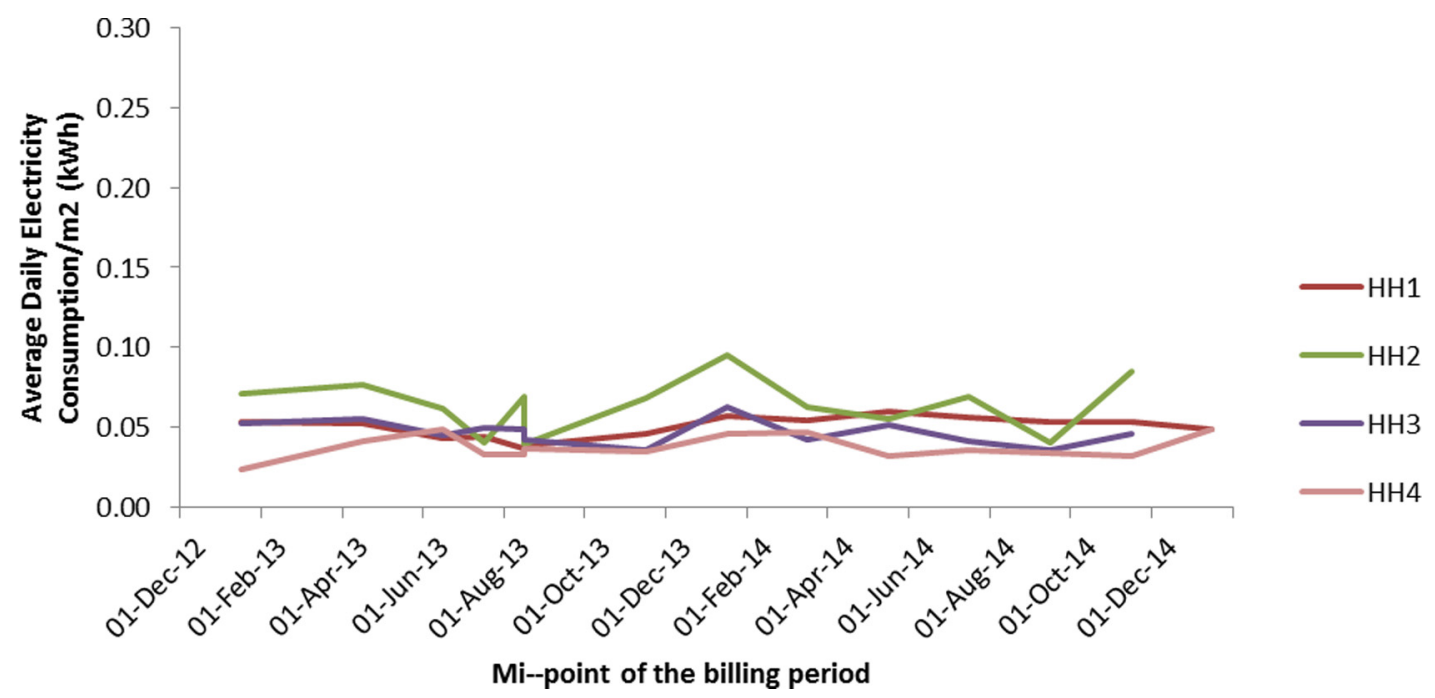

Fig. 3. Average daily electricity consumption (kWh) by regular electricity users.

video games, stereos, TVs, Foxtel and set-top boxes, etc. Laundry included washing machines, dryers and irons. Lastly, dishwashers, microwaves, electric ovens, rice cookers, electric kettles, slow cookers, coffee makers, toasters, sandwich makers, mixers, vacuum cleaners, garage door openers and other small appliances used in some dwellings, were grouped as other appliances. Figure 5 presents various appliances used by the sample households.

\subsubsection{Standby power in the surveyed dwellings}

Generally, appliances can be in four power modes [4]: inuse, active stand-by, passive stand-by and off. Without the knowledge of consumers, appliances left in standby mode drew power 24 hours a day and 7 days a week, resulting in high electricity bills. Many of these appliances use stand-by power for showing the internal clock or to 


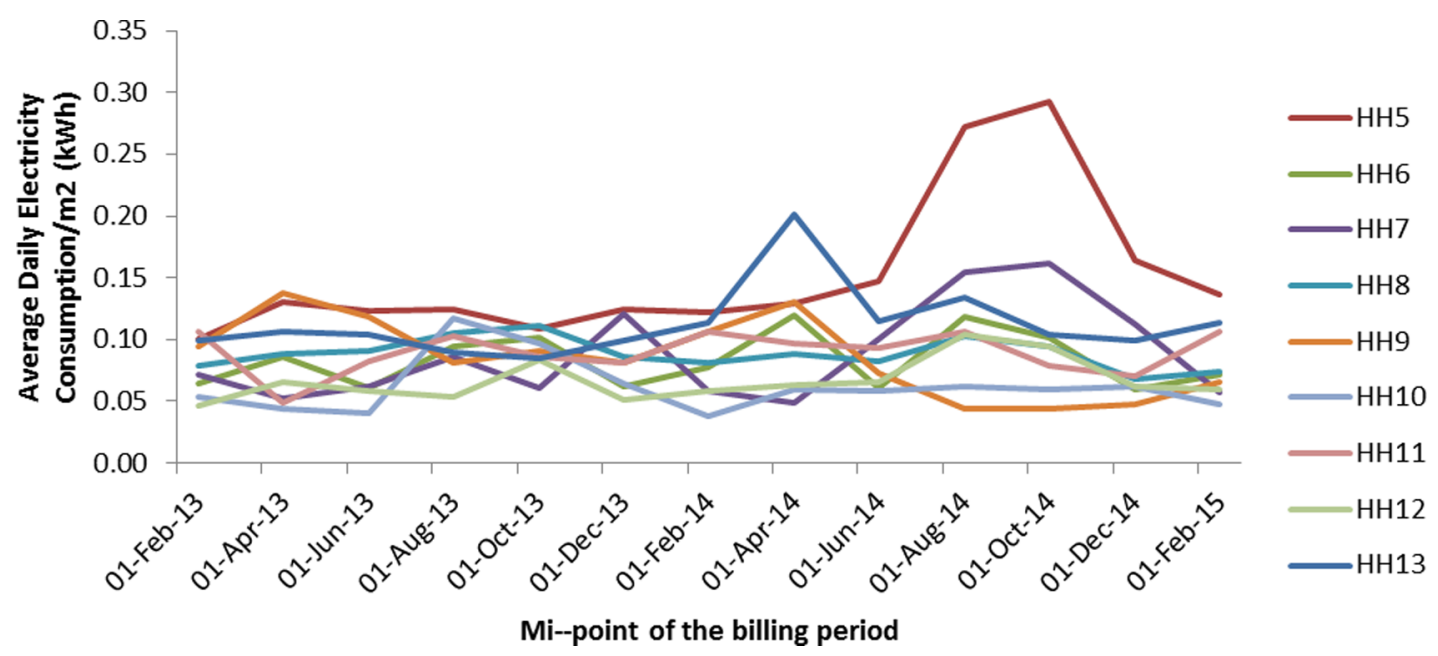

Fig. 4. Average daily electricity consumption (kWh) by extreme electricity users.

Table 1. Summary of building and occupancy related factors in the dwellings participated in energy audit.

\begin{tabular}{|c|c|c|c|c|c|c|c|c|c|}
\hline $\mathrm{HH}$ & $\begin{array}{l}\text { Orientation/ } \\
\text { dwelling type }\end{array}$ & $\begin{array}{l}\text { Ext. wall } \\
\text { insulation }\end{array}$ & $\begin{array}{l}\text { Ceiling } \\
\text { insulation }\end{array}$ & $\begin{array}{l}\text { Star } \\
\text { rating }\end{array}$ & $\begin{array}{l}\text { Hot water } \\
\text { system }\end{array}$ & $\begin{array}{l}\text { No. of } \\
\text { occupants }\end{array}$ & $\begin{array}{l}\text { Year of } \\
\text { construction }\end{array}$ & $\begin{array}{l}\text { Heating } \\
\text { system }\end{array}$ & $\begin{array}{l}\text { Cooling } \\
\text { system }\end{array}$ \\
\hline 1 & North-east/SD & No & R.4 & 6.5 Stars & $\begin{array}{l}\text { Gas boosted } \\
\text { SWH }\end{array}$ & 8 & 2010 & $\times$ & Fan \\
\hline 2 & South/SD & No & - & - & Gas HWS & 2 & 2008 & $\mathrm{RAC}^{1}$ & $\mathrm{RAC}+\mathrm{Fan}$ \\
\hline 3 & North/SD & No & $\mathrm{R} 4.0$ & 6.5 Stars & $\begin{array}{l}\text { Electric heat } \\
\text { pump }\end{array}$ & 2 & 2011 & $\mathrm{GH}$ & $\mathrm{EC}+2^{*}$ Fan \\
\hline 4 & South-east & No & - & - & Gas HWS & 2 & 2010 & GH & $\mathrm{EC}^{4}+\mathrm{Fan}$ \\
\hline 5 & South-west/SD & No & R3.0 & 5 Stars & Gas HWS & 4 & 2008 & $\mathrm{ERH}^{3}$ & Fan \\
\hline 6 & South & $\mathrm{R} 1$ & $\mathrm{R} 4.0$ & 6 Stars & $\begin{array}{l}\text { Electric } \\
\text { boosted SWH }\end{array}$ & 3 & 2010 & $\begin{array}{l}\mathrm{RAC}+2^{*} \\
\mathrm{ERH}\end{array}$ & $\begin{array}{l}\mathrm{RAC}+2^{*} \\
\mathrm{EC}+5^{*} \text { Fan }\end{array}$ \\
\hline 7 & North-east & No & $\mathrm{R} 4.0$ & 7 Stars & Gas HWS & 5 & 2011 & $\mathrm{ERH}$ & $2^{*}$ Fan \\
\hline 8 & North-west & No & - & - & Gas HWS & 6 & 2008 & $\mathrm{ERH}$ & $4^{*} \operatorname{Fan}$ \\
\hline 9 & North & $\mathrm{R} 1.3$ & $\mathrm{R} 4.0$ & 6 Stars & $\begin{array}{l}\text { Gas boosted } \\
\text { SWH }\end{array}$ & 2 & 2010 & $\times$ & $\mathrm{EC}+2^{*}$ Fan \\
\hline 10 & South-west & No & - & - & Gas HWS & 6 & 2008 & ERH & $x$ \\
\hline 11 & East/TH & No & $\begin{array}{l}\text { Plasterboard } \\
\text { R2.5 }\end{array}$ & 5 Stars & Gas HWS & 1 & 2008 & $\begin{array}{l}2^{*} \mathrm{RAC} \\
+\mathrm{GH}^{2} \\
+\mathrm{ERH}\end{array}$ & $2^{*} \mathrm{RAC}$ \\
\hline 12 & West & No & $\mathrm{R} 4.0$ & 6 Stars & Gas HWS & 6 & 2010 & $\times$ & Fan \\
\hline 13 & North-west & No & - & 7 Stars & Gas HWS & 4 & 2011 & $\mathrm{RAC}$ & $\mathrm{RAC}$ \\
\hline
\end{tabular}

1. Reverse Cycle Air-conditioner (RAC) 2. Gas Heater 3. Electric Resistive Heater 4. Evaporative Cooler.

receive the remote control signals. However, sometimes there is no obvious sign of continuous power consumption and a meter is needed to be certain. In Australia, over $10 \%$ of the electricity consumption by households is attributed to standby power consumption by the appliances [5]. In order to incorporate the standby power usage into the energy audit of the sample dwellings, were applicable, standby energy for each appliance was collected from related websites using the model number of the appliances.

\subsubsection{Distribution of electricity consumption according to orientation}

In order to justify the distribution of electricity consumption in the sample dwellings, the result of walk-through audit was evaluated concurrently in the dwellings having similar orientation. Therefore, the influence of other factors on households' electricity consumption such as the type and number of the appliances, as well as the occupants' behaviour with respect to the use of appliances was better justified. 


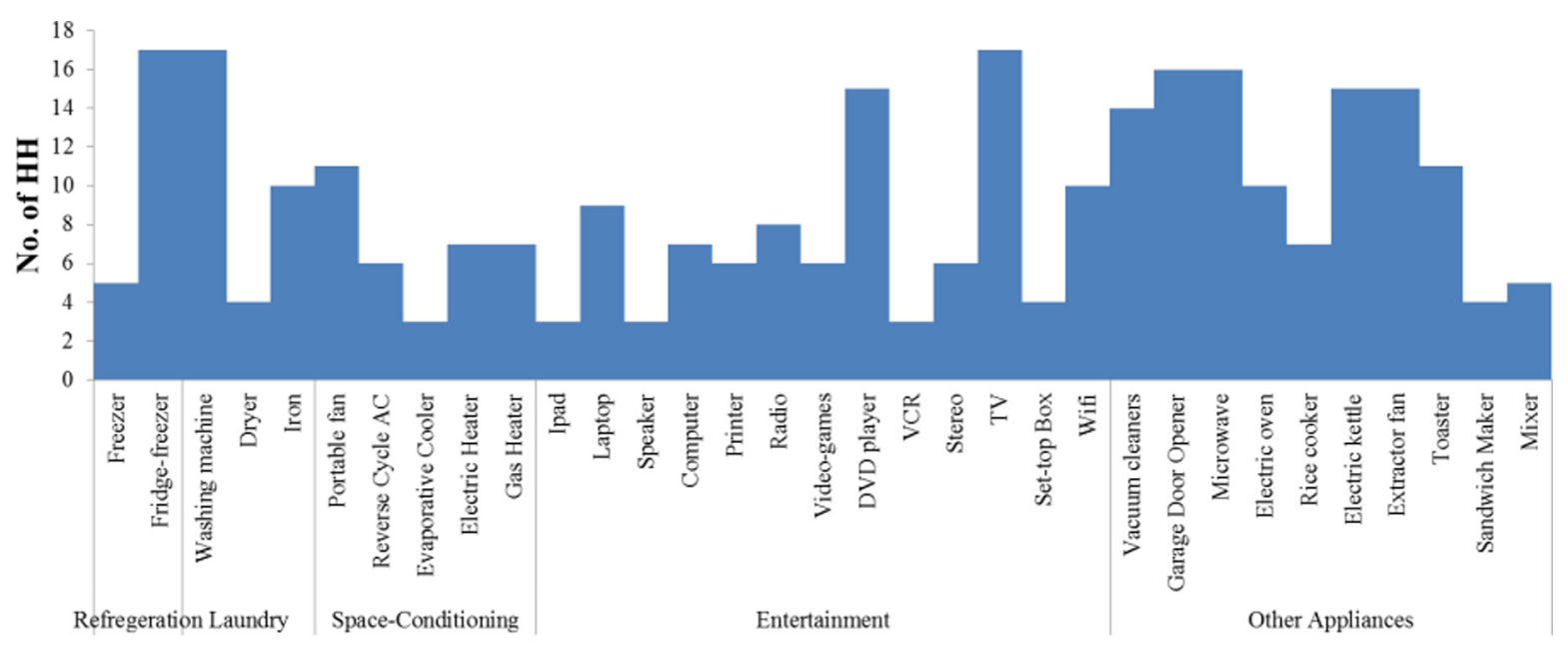

Electronic Appliances

Fig. 5. Different appliances used in the sample dwellings.

\subsubsection{Group 1: south-facing dwellings: households 2 and 6}

These two south-facing dwellings have different star ratings at the design stage (i.e., 5 and 6 -stars for households 2 and 6 , respectively). Analysis of historical electricity consumption data during 2013-14 revealed that the $\mathrm{ADEC} / \mathrm{m}^{2}$ in these two dwellings followed an approximately similar trend, with both of the households experienced the maximum consumption in extreme seasons. In summer, more than half of the electricity (57\%) used in HH2 was spent on space cooling, which was significantly higher than in HH6 (36\%). On the other hand, with HH2 owning variety of entertainment devices (e.g., Telstra-tab, 2 laptops, blue ray disk, media player computer, 2 stereo and amplifier, 3 TVs, etc.), these appliances stood out as the second intensive electricity users in this household (23\% and $45 \%$ in summer and winter, respectively). Laundry appliances (i.e., washing mashing and iron), however, was the second highest electricity users in HH6 (about one-fifth of the electricity in summer and $16 \%$ in winter in HH6 was attributed to the appliances grouped as laundry). The result of energy audit further revealed that although $\mathrm{HH} 2$ has more electronic devices that could potentially leave on standby (e.g., entertainment appliances), HH6 spent significantly higher on standby power consumption $(9 \%$ and $7 \%$ against $1 \%$ and $3 \%$ in $\mathrm{HH} 2$ during summer and winter, respectively).

\subsubsection{Group 2: south-west facing dwellings: households 5 and 10}

While HH5 live in a 5-star dwelling, no evidence was found on the star rating of HH10 (with introduction of 5-star energy ratings requirements for new homes in Western Australia in 2006, it is assumed that this building also achieved at least 5-star rating).

A comparison between electricity consumption in these two south-west facing buildings shows sudden changes in the electricity consumption by each of these households during 2013-14. In HH5, this change started in May 2014 and reached to its maximum in September 2014. The peak consumption in HH10, however, occurred in June 2013.

Distribution of electricity consumption in each household was standalone. HH5 spent more than half of its electricity consumption in summer and less than a fourth in winter on entertainment (mainly personal computers used by children, TVs, VCR, etc.). Household 10, however, spent significantly less on this group of appliances $(20 \%$ and $18 \%$ in summer and winter, respectively). In summer, HH4 used only 1 standing fan, which constituted to only $4 \%$ of electricity consumption. However, no cooling system was used in HH10. In winter, on the other hand, HH5 spent half of its electricity on space heating though using two identical 1800-2000 W electric heaters running on average $10 \mathrm{~h} /$ day. This was significantly higher compare to HH10 that spent only $8 \%$ of its electricity on space heating.

\subsubsection{Group 3: north-east facing dwellings: households 1} and 7

Both of these dwellings obtained a reasonably high star rating at the early design stage (6.5-stars for household 1 and 7-stars for household 7). Except a sudden reduction in August 2013 (to $0.04 \mathrm{kWh} / \mathrm{m}^{2} /$ day), electricity consumption in HH1 was almost stable during 2013-14. In the time, HH7 experienced two sudden rises in its electricity consumption. Firstly, in October 2013, the ADEC in this household rose to $0.12 \mathrm{kWh} / \mathrm{m}^{2} /$ day. After a quick fall in March 2014, the ADEC in this household increased over again to $0.16 \mathrm{kWh} / \mathrm{m}^{2}$ day in September 2014 .

With two fridge-freezer (348 and $130 \mathrm{~W}$ ) running simultaneously in HH1, a significant proportion of electricity in this household was spent on refrigeration (36\% and $45 \%$ in summer and winter, respectively). This was, however, higher than the electricity used by refrigeration in $\mathrm{HH} 7$ with a $235 \mathrm{~W}$ fridge-freezer $(20 \%$ and $6 \%$ of the total household electricity consumption in summer and winter). Both of the households used fans to cool down the house in summer. In 
winter, on the other hand, no heating system was used in $\mathrm{HH} 1$. However, $62 \%$ of the electricity consumption in $\mathrm{HH} 7$ was attributed to space heating (in winter, a 1500-W ceramic fan heater was on average used for $10 \mathrm{~h} /$ day).

\subsubsection{Group 4: north-west facing dwellings: households 8 and 13}

HH8 had a steady consumption trend. HH13, however, experienced a peak in its ADEC in February 2014. Findings from energy audit were in line with the result of historical electricity consumption analysis. Only a small portion (14\%) of electricity used by HH8 was attributed to space cooling in summer. In winter, however, nearly a third of the electricity in this household was spent on space heating. Household 13 on the other hand, spent more on space cooling than space heating (37\% on space cooling in summer against $16 \%$ on space heating in winter). Being highly concerned about the standby power consumption as well as the energy used by lightings, HH13 spent only $1 \%$ of its electricity on the standby power, which was lower than HH8 (around 4\%).

\subsubsection{Group 5: north-facing dwellings: households 3 and 9}

The star-rating attributed to these two north-facing dwellings at the early design stage was 6.5 and 6 . The maximum average daily electricity usage in $\mathrm{HH} 3$ was $0.06 \mathrm{kWh} / \mathrm{m}^{2} /$ day, which significantly increased to $0.14 \mathrm{kWh} / \mathrm{m}^{2} /$ day in HH9. Both of the households, however, experienced their highest consumption in summer.

In summer, a significant proportion of electricity used in both of these households was spent on space cooling ( $49 \%$ and $59 \%$ in HH3 and HH9, respectively) thorough a portable air conditioner and 2 fans in $\mathrm{HH} 3$ and a $1330-\mathrm{W}$ portable air conditioner running on average 12 hours a day in HH9. This was then, followed by refrigeration $(20 \%$ and $16 \%$ in $\mathrm{HH} 3$ and $\mathrm{HH} 9)$, other appliances $(12 \%$ and $10 \%$ in HH3 and HH9) and entertainment (8\% and $9 \%$ in HH3 and HH9). No heating system was used in any of the dwellings.

\subsubsection{Group 6: east-facing dwelling: household 11}

The ADEC in this 5-star dwelling ranged between 0.05 and $0.11 \mathrm{kWh} / \mathrm{m}^{2} /$ day. Furthermore, no significant difference was observed between the household's consumption trend in 2013 and 2014. While the minimum electricity was used in mid-seasons, the maximum consumption was experienced with a minor difference in summer $\left(0.11 \mathrm{kWh} / \mathrm{m}^{2} /\right.$ day in summer 2013 and 2014) and winter (0.10 and $0.11 \mathrm{kWh} / \mathrm{m}^{2} /$ day in 2013 and 2014, respectively). A large proportion of electricity in HH3 was spent on space heating and cooling ( $79 \%$ and $83 \%$ in summer and winter, respectively). This clearly verifies the findings from historical electricity consumption analysis, in which, the maximum electricity was used in extreme seasons. Appliances such as microwave, electric kettle, toaster and vacuum cleaner constituted about $8 \%$ of the electricity consumption in summer and $6 \%$ in winter, followed by entertainment (4\%).

\subsubsection{Group 7: west-facing dwelling: household 12}

The average daily electricity consumption in this 6-star dwelling ranged between 0.05 and $0.08 \mathrm{kWh} / \mathrm{m}^{2} /$ day in 2013 and between 0.06 and $0.1 \mathrm{kWh} / \mathrm{m}^{2} /$ day in 2014 . An inconsistency was found between the result of historical electricity consumption analysis and the findings from energy audit in this household. Although no heating system was reported during the energy audit, analysis of historical electricity consumption data showed a significant increase in the average electricity consumption in winter (the ADEC was 12.9 and $16.6 \mathrm{kWh}$ /day in summer and winter 2013 and 12.6 and $20.6 \mathrm{kWh}$ /day in summer and winter 2014), suggesting that the building was perhaps heated in winter. Lighting constitutes $4 \%$ and $5 \%$ of the ADEC in summer and winter, respectively.

\subsubsection{Group 8: south-east facing dwelling: household 4}

As supported by the historical electricity consumption data, the average daily electricity consumption in this household during 2013-14 was stable (ranged between 0.03 and $0.05 \mathrm{kWh} / \mathrm{m}^{2} /$ day). However, the household experienced its maximum electricity consumption in summer during both 2013 and 2014. Although the major portion of electricity in summer was spent on cooling the house by a portable evaporative cooler (32\%), no electric heating system was used in winter (a gas heater was used instead). Entertainment appliances including 2 laptops, video game, 2 TVs, DVD player, etc., were the second highest electricity consumers in summer, and the first one in winter (30\% and $37 \%$ in summer and winter, respectively). It was also found that a significant difference existed between the electricity consumption by the appliances grouped as laundry during summer and winter. Findings from the energy audit revealed that the existing difference is mainly attributed to the dryer, which was used for an average $2 \mathrm{~h}$ on winter days.

\subsection{Guidelines for improving households energy performance}

The above results showed that electricity consumption, as the main source of energy, significantly varies in the sample dwellings. This can be attributed to occupant's energy use patterns and their socio-economic condition. Households with different socio-economic characteristics used diverse electronic appliances in different ways and resulted in different types of energy consumption patterns. In order to assist the households with their daily energy usage, mostly the portion spent on heating and cooling of the house in extreme seasons, a general guideline was developed to address the perceived inefficacies in the households. This guideline was then tailored based on the specific requirements of each household and communicated to each household separately. Table 2 presents a summary of these general guidelines. 
Table 2. Guidelines for energy conservation in social housing dwellings.

\begin{tabular}{ll}
\hline Dos and don'ts in winter & Dos and don'ts in summer \\
\hline Open all the curtains and blinds & $\begin{array}{l}\text { Close all the doors, windows and blinds } \\
\text { in the morning }\end{array}$ \\
in the morning before it is getting too hot!
\end{tabular}

Generic guidelines

Test the windows or door for

leaks by burning an incense

stick or a candle; If the

smoke flickers, you have an air leak:

- Tighten up around the windows and doors by adding new weather-stripping

Close them all in the evening

Close all the windows and curtains before turning on the heater

Set the heater on:

- $20^{\circ} \mathrm{C}$ in kitchen/living area

- $15-18^{\circ} \mathrm{C}$ in bedrooms

If applicable, adjust the heaters louvers down towards the floor

Only heat up the rooms in use and close the openings to the cooler rooms. It saves up to $75 \%$ of the heat loss!

Use heavy curtains to reduce heat loss through window

Choose the heater carefully! Unlike the purchase price that is minimum in case of portable heater, gas heater and reverse-cycle AC, respectively, the running cost of these appliances is maximum in turn!
Open the windows and curtains again in the evening and night

Cool the house by shading the east and west windows

Set the temperature at around $25^{\circ} \mathrm{C}$

Install the air conditioner on the shady side of the house

Only cool down the rooms in use and close the openings to other rooms.

Close all curtains to prevent heat gain through window

Economical cooling appliances are: fan, evaporative cooler, reverse-cycle AC
Use washing machine with

full load

Say NO to cloth dryers! Hang the cloths outside

Switch off the appliances at the wall or power strips

Avoid opening the oven door when cooking

Unplug the charger when your mobile phone is fully charged.

Set fridge temperature to 4 or $5^{\circ} \mathrm{C}$ and freezer temperature

-15 to $-18^{\circ} \mathrm{C}$. Every degree lower that uses around $5 \%$ more energy

Use energy efficient lamps

(CFL or LED)

\section{Conclusion}

Energy consumption in the sample dwellings follows different patterns. Irrespective of orientation, heating/ cooling was found to constitute a significant proportion of electricity consumption in the majority of the sample dwellings. The proportion of electricity spent on cooling ranged between $0 \%$ and $59 \%$ in south facing and north facing dwellings, respectively. Heating contributed to 0 $83 \%$ of the households' electricity consumption $(0 \%$ in north-eat facing, west facing and south-east facing dwellings and $83 \%$ in an east facing dwellings). Results from walk-through energy audit further revealed that households with different socio-economic characteristics use energy in different ways. This diversity ranges from the type of appliances, to how they are used in the households and their time of use. Confirmed by direct observations, it was also found that the participated households have substantially different level of concern about energy usage. Unlike energy savvy households who closely monitor their daily energy consumption, some pay no attention to their usage, putting it far behind their comfort. Occupants were educated through proposed practical low-cost guidelines in order to reduce their energy consumption in their households. Although the extent to which households are open to "culture change" for further energy conservation varied, a certain level of follow up was required to ensure that the proposed changes had been deployed in households' daily life.

\section{References}

1. ABS, 4604.0 - Energy Account, Australia, 2014-15: Australia becomes more energy efficient, 2017, http://www.abs.gov. au/ausstats/abs@.nsf/lookup/4604.0Media\%20Re lease12014-15 (retrieved on: 2017/23/02)

2. D. Brounen, N. Kok, J.M. Quigley, Residential energy use and conservation: economics and demographics, Eur. Econ. Rev. 56, $931(2012)$ 
3. P. Esmaeilimoakher, T. Urmee, T. Pryor, G. Baverstock, Identifying the determinants of residential electricity consumption for social housing in Perth, Western Australia, Energy Build. 133, 403 (2016)

4. Government of South Australia-Department of State Development, Stand-by power, 16 March 2016, https://www.sa. gov.au/topics/water-energy-and-environment/energy/sav ing-energy-at-home/household-appliances-and-other-energyusers/stand-by-power \#title2
5. Australian Bureau of Statistics, Use of appliances and white goods in Australian homes, 4614.0.55.002 - Energy in Focus: Energy Efficiency of Australian Homes, April 2010, http://www.abs.gov.au/ausstats/abs@.nsf/ Latestproducts/4614.0.55.002Main\%20Features5Apr\% 202010? opendocument\&tabname $=$ Summary \&prodno $=$ 4614.0.55.002\&issue $=$ Apr $\% 202010 \&$ num $=\& v i e w=$

(retrieved on: 2010/30/04)

Cite this article as: Parisa Esmaeilimoakher, Tania Urmee, Trevor Pryor, Garry Baverstock, Influence of occupancy on building energy performance: a case study from social housing dwellings in Perth, Western Australia, Renew. Energy Environ. Sustain. 2, 44 $(2017)$ 